\title{
Memory for Proprioceptive Targets in Bulimia Nervosa
}

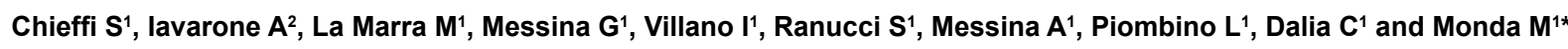

${ }^{1}$ Department of Experimental Medicine, Section of Human Physiology, Second University of Naples, Via Costantinopoli 16, 80138 Naples, Italy ${ }^{2}$ Neurological and Stroke Unit, CTO Hospital, AORN "Ospedali dei Colli, Naples, Italy

\begin{abstract}
Objective: Disorders of body representation are reported in bulimia nervosa. Body representation is given by the integration and synthesis of multiple sensory inputs, which include proprioceptive, vestibular, tactile and visual information. The present study aimed to investigate whether a disorder of proprioceptive processing could be observed in bulimia nervosa.
\end{abstract}

Methods: Bulimic patients and healthy participants were asked to remember the location of proprioceptive presented targets. We measured constant, variable and absolute distance and direction errors.

Results: Results showed an increase of variable distance and direction errors, and absolute direction error, in bulimic patients with respect to healthy participants.

Conclusions: The reduced efficiency in storing of proprioceptive information could contribute to the disorder of body representation in bulimia nervosa.

Keywords: Eating disorders; Bulimia nervosa; Proprioception; Body representation; Body schema; Memory

\section{Introduction}

At every instant, each individual holds a precise knowledge about his own body, ranging from the consciousness of its unity to the awareness of the position that the body and its segments occupy in space. This self-image is the product of the integration and synthesis of multiple sensory and motor inputs (i.e., proprioceptive, vestibular, tactile, visual, efference copy). However, alongside the perceptual image, each individual feels the conscious experience of his own body due to the contribute of imaginative and intellective factors. To this set of knowledge various denominations have been attributed, including the terms of "body schema" [1], "image of oneself" [2], "postural scheme" [3], "image of our own body" [4]. Currently, in neuropsychological research prevails the distinction between body schema and body image. Following Coslett et al. [5-7] body schema can be defined as a dynamic representation of the relative positions of body parts derived from sensory and motor inputs that interacts with motor systems in the genesis of actions; from the other hand, body image can be defined as a lexical-semantic representation of the body including body part names, functions, and relations with artefacts [5-7].

Patients with bulimia nervosa may exhibit disorders of body representation [8-12]. Bulimia nervosa is a persistent disturbance of eating or eating-related behavior that results in the altered consumption of food. Eating behavior can be defined as the "thoughts, actions, and intents that an organism enacts in order to ingest solids or liquids" [13]. It is a complex phenomenon with physiological [14-21], psychological, social, as well as sociocultural features [22,23]. According to the Diagnostic and Statistical Manual of Mental Disorders, 5th edition (DSM-5) [24], bulimia nervosa is characterized by the presence of period of dieting and fasting interrupted by binge-eating episodes, in which a large amount of food is eaten. Binge-eating episodes are accompanied by a feeling of loss of control and compensated by self-induced vomiting, laxative, diuretic, or other medication abuse or, more rarely, nonpurging strategies like exercising and dieting. Individuals with bulimia nervosa place an excessive emphasis on body shape or weight in their self-evaluation. Further, experimental evidence suggests the presence of disorders of body representation. Generally, by using whole-image adjustment methods, bulimic patients show an overestimation of their body size and a greater body dissatisfaction [2528]. However, the neurophysiological and neuropsychological bases of body representation disorders are still unclear.

This study aimed at investigating body schema representation in bulimic patients by examining their ability to represent the body in space, which is based on an internal representation of body position derived primarily from proprioceptive information. At first, the experimenter passively moved the participant's hand up to the target position; then participants were asked to return actively to the target position. In this case, proprioceptive information about target position was stored in working memory. We examined if the storing of proprioceptive information was less efficient in bulimic patients than in healthy controls. We hypothesized that a reduced efficiency in storing of proprioceptive information could contribute to the disorder of body schema representation in bulimia nervosa.

\section{Methods}

\section{Participants}

Participants were 12 female patients with bulimia nervosa (2027 years, mean=24.5, SD=1.9) consecutively seen at the Service of nutrition of the Second University of Naples during the period January 2014-January 2015. They were matched with 12 women comparable by age (19-27 years, mean $=24.2, \mathrm{SD}=2.0$ ) recruited among friends of patients. Diagnosis of bulimia was reached according to DSM-5 criteria [24] by a certified psychiatrist, expert of feeding

*Corresponding author: : Marcellino Monda, MD, Dipartimento di Medicina Sperimentale, Sezione di Fisiologia Umana, Seconda Università di Napoli, Via Costantinopoli 16, 80138 Napoli, Italy, Tel: 39815665804; E-mail: marcellino.monda@unina2.it

Received April 24, 2015; Accepted May 30, 2015; Published June 06, 2015

Citation: Chieffi S, lavarone A, La Marra M, Messina G, Villano I, et al. (2015) Memory for Proprioceptive Targets in Bulimia Nervosa. J Psychiatry 18: 297 doi: 10.4172/2378-5756.1000297

Copyright: ( 2015 Chieffi S, et al. This is an open-access article distributed under the terms of the Creative Commons Attribution License, which permits unrestricted use, distribution, and reproduction in any medium, provided the original author and source are credited 
disorders. Exclusion criteria were the presence of significant medical, neurological or psychiatric disorders able to account for secondary disorders of nutrition. For each participant, we evaluated the Body Mass Index (BMI), which is the weight over the squared height ratio (BMI, bulimic patients: $19.3-29.8$, mean $=22.1, \mathrm{SD}=3.2$; controls: 18.6 24.7, mean=22.3, $\mathrm{SD}=1.6$ ). All participants were right-handed. Hand dominance was assessed by administering the Edinburgh Handedness Inventory [29]. The study was approved by the ethics committee and was carried on in accordance with the 1964 Declaration of Helsinki. Participants gave written informed consent to take part in the study.

\section{Apparatus}

Participants' movements were recorded using a digitising tablet. The tablet measured $430 \mathrm{~mm}$ (width) $\times 570 \mathrm{~mm}$ (depth) and had an active surface of $305 \times 458 \mathrm{~mm}$. It was contacted with a non-inking electronic stylus. When in contact, the position of the stylus tip was sampled at a rate of $50 \mathrm{~Hz}$. Data were recorded in horizontal and vertical co-ordinates with accuracy of $0.25 \mathrm{~mm}$. The tablet was covered with a thin white card on which the starting position and the target locations (3-mm diameter spots) were drawn in black ink. Starting position was at $20 \mathrm{~cm}$ from the trunk along the mid-sagittal axis. Target distance and direction were paired pseudo randomly in order to minimize possible symmetric patterns, which might assist location memory.

\section{Procedure}

Testing was conducted in a laboratory of the Department of Experimental Medicine, Second University of Naples. The participants were blindfolded and sat in front of a table on which the digitising tablet was placed. The subjects held the stylus with the right hand. The experimenter placed the subject's hand on the starting position and passively moved it up to the target position (criterion movement). Then, the experimenter brought the subject's hand back to the starting position. After a time delay of 3-s or 30-s, the subject was asked to return actively to the target location (reproduction movement). There was one block of 14 trials for each delay condition: on 7 trials the target was localized in the left hemispace and on the remaining 7 trials in the right hemispace. The sequence of hemispace locations was randomized. The order of the two blocks was counterbalanced across the subjects.

Pointing errors were decomposed into their radial and angular components. The dependent variables employed were: constant (signed), variable and absolute (unsigned) percentage radial (i.e., distance) errors, and constant, variable and absolute angular (i.e., direction) errors. Errors were measured with reference to the finger starting position. For constant distance errors, reaching errors farther than the target location were assigned plus values, whereas errors nearer than the target location were assigned minus values. For constant direction errors, reaching errors in the direction away from the median sagittal axis, both in the left and in the right hemispace, were given plus values. Data for each delay condition were pooled across left and right target locations. The standard deviation of the constant distance and direction errors calculated for each condition was the variable distance and direction errors. Variable errors quantify the scatter of pointing errors and are sensitive to variability or inconsistency in responding.

\section{Statistical analyses}

A mixed design $2 \times 2$ ANOVAs were conducted on distance and angular errors with Group (bulimic patients, controls) as betweensubject factor, and Delay (3-s, 30-s) as within-subject factor. Paired comparisons were performed using the Newman-Keuls procedure. Significance level was fixed at $\mathrm{p}<0.05$.

\section{Results}

The values of distance and direction errors are showed in Table 1.

\section{Distance errors}

Neither Group $(F(1,22)=0.897, n s)$ nor Delay $(F(1,22)=0.388, n s)$ affected constant distance error, and the interaction between the two factors was not significant $(\mathrm{F}(1,22)=1.013, \mathrm{~ns})$.

Both Group ( $\mathrm{F}(1,22)=10.054, \mathrm{p}<0.01$ : Controls $=14.3 \%$, Bulimic patients $=17.8 \%)$ and Delay $(\mathrm{F}(1,22)=4.598, \mathrm{p}<0.05: 3-\mathrm{s}=14.8 \%, 30-\mathrm{s}$ $=17.4 \%)$ influenced variable distance error. There was no significant interaction $(\mathrm{F}(1,22)=0.687$, n.s $)$

No significant main effects were found on absolute distance error (Group: $\mathrm{F}(1,22)=0.071$, ns; Delay: $\mathrm{F}(1,22)=1.058, \mathrm{~ns})$, and there was no significant interaction $(\mathrm{F}(1,22)=0.932, \mathrm{~ns})$.

\section{Direction errors}

Neither Group $(\mathrm{F}(1,22)=0.124, \mathrm{~ns})$ nor Delay $(\mathrm{F}(1,22)=0.084, \mathrm{~ns})$ affected constant direction error, and the interaction between the two factors was not significant $(\mathrm{F}(1,22)=1.376, \mathrm{~ns})$.

Both Group ( $\mathrm{F}(1,22)=7.276, \mathrm{p}<0.02$ : Controls $=5.6^{\circ}$, Bulimic patients $\left.=6.9^{\circ}\right)$ and Delay $\left(\mathrm{F}(1,22)=68.630, \mathrm{p}<0.00001: 3-\mathrm{s}=5.0^{\circ}, 30\right.$ $\left.s=7.5^{\circ}\right)$ influenced variable direction error. There was a significant interaction between the two factors $(\mathrm{F}(1,22)=4.708, \mathrm{p}<0.05)$. Posthoc comparisons showed that in both groups variable direction error increased with delay. Further, at the 3-s delay condition variable direction error in the control group did not differ from that in the bulimic group. Conversely, at the 30 -s delay condition variable distance error in the bulimic group was greater that that in the control group $(\mathrm{p}<0.01)$.

Also absolute direction error was influenced by both Group (F $(1,22)=8.569, \mathrm{p}<0.01$ : Controls $=5.1^{\circ}$, Bulimic patients $\left.=6.4^{\circ}\right)$ and Delay $\left(\mathrm{F}(1,22)=82.734, \mathrm{p}<0.00001: 3-\mathrm{s}=4.4^{\circ}, 30-\mathrm{s}=7.0^{\circ}\right)$. There was a significant interaction between the two factors $(F(1,22)=4.346$, $\mathrm{p}<0.05)$. Post-hoc comparisons showed that in both groups absolute direction error increased with delay. Further, at the 3-s delay condition absolute direction error in the control group did not differ from that in the bulimic group. Conversely, at the 30-s delay condition absolute direction error in the bulimic group was greater that that in the control group $(\mathrm{p}<0.01)$.

\section{Discussion}

Target position may be coded in either an egocentric, i.e. with reference to the position of the body [30-32], and allocentric, i.e. with reference to the surrounding environment independently from the subject's location or viewpoint [33-44], frame of reference. The present study focused on memory for proprioceptively presented, egocentric target locations in bulimic patients. The results showed a

\begin{tabular}{|c|c|c|c|c|}
\hline \multirow{2}{*}{ Group Delay } & \multicolumn{2}{|c|}{ Controls } & \multicolumn{2}{c|}{ Bulimic patients } \\
\cline { 2 - 5 } & $\mathbf{3 ~ s}$ & $\mathbf{3 0 ~ s}$ & $\mathbf{3 ~ s}$ & $\mathbf{3 0 ~ s}$ \\
\hline Constant distance error (\%) & $7.7(7.2)$ & $8.2(7.2)$ & $6.9(5.8)$ & $4.8(5.5)$ \\
\hline Variable distance error (\%) & $13.5(3.5)$ & $15.1(3.6)$ & $16.0(4.8)$ & $19.6(4.0)$ \\
\hline Absolute distance error (\%) & $13.4(3.9)$ & $13.4(4.5)$ & $12.7(4.0)$ & $14.8(3.1)$ \\
\hline constant direction error (degree) & $1.3(1.6)$ & $1.7(2.0)$ & $2.2(2.4)$ & $1.5(4.2)$ \\
\hline variable direction error (degree) & $4.6(1.2)$ & $6.5(0.6)$ & $5.3(1.4)$ & $8.5(2.1)$ \\
\hline absolute direction error (degree) & $4.1(1.0)$ & $6.1(1.0)$ & $4.8(1.4)$ & $8.0(1.6)$ \\
\hline
\end{tabular}

Table 1: Mean values of distance and direction errors measured in the experiment (standard deviations in brackets). 
reduced efficiency in storing target locations by using proprioceptive information in bulimic patients as compared to healthy participants. This was supported by the finding that at the 30-s delay condition both absolute and variable direction errors were greater in bulimic patients than in controls. Conversely, at the 3-s delay condition both absolute and variable direction errors did not differ between the two groups. In other words, proprioceptive direction information stored in working memory appeared to degrade more rapidly in bulimic patients than in healthy participants. Further, variable distance error in bulimic patients was greater than that in controls.

Proprioceptive information is a major factor that contributes to the elaboration of body schema representation. Muscle receptors seem to be the main contributors to proprioception [45], while cutaneous and joint receptors appear to play only a subsidiary role [46]. There are two main types of muscle receptors, namely, the primary (group Ia) and the secondary (group II) sensory endings in muscle spindles. The secondary endings contribute mainly to limb position information, while the muscle spindle primaries provide relatively more information on limb velocity [45]. The importance of proprioceptive input for body awareness is attested by enduring changes caused by short-lasting muscle vibration and other somatic manipolation [47]. Lackner [47] found that muscle vibration generated proprioceptive misinformation about limb position and induced systematic perceptual distortions of the body.

The disorder of storage in proprioceptive working memory found in bulimic patients might contribute to the alteration of body representation that has been observed in these patients. This hypothesis is supported by from functional neuroimaging studies showing a parietal cortical hypofunction in bulimia nervosa [48,49]. Delvenne et al. [48] evaluated, at rest, brain glucose metabolism in patients with bulimia nervosa. In comparison with control subjects, bulimic patients showed global and regional absolute hypometabolism of glucose. Further, in relative values, only parietal cortex metabolism was significantly lower in bulimic patients. Parietal cortex is implicated in the processing of proprioceptive information and in body representation [50,51]. Disorders of body representation such as autotopagnosia, finger agnosia and left-right disorientation may result from lesions of the left parietal cortex; disturbances such as anosognosia for hemiplegia, feelings of non-belonging, somatoparaphrenia and hemisomatoagnosia from lesions of the right parietal cortex [52].

\section{Conclusion}

The data of the present study showed a reduced efficiency in storing proprioceptive information about target location in bulimic patients as compared to healthy participants. It is possible that the reduced efficiency in proprioceptive processing may contribute to the disorder of body representation in bulimia nervosa.

\section{References}

1. Schilder P (1935) The image and appearance of the human body. New York International University Press.

2. Van Bogaert L (1934) Sur la pathologie de l'image de soi. Ann Med Psychol 92: 719-759.

3. Head H, Holmes G (1911) Sensory disturbances from cerebral lesions. Brain 34: $102-254$

4. Lhermitte J (1942) De l'image corporelle. Rev Neurol 74: 20-38.

5. Coslett HB, Saffran EM, Schwoebel J (2002) Knowledge of the human body: A distinct semantic domain. Neurology 59: 357-363.

6. Schwoebel J, Boronat CB, Coslett HB (2002) The man who executed "imagined" movements: Evidence for dissociable components of the body schema. Brain Cogn 50: 1-16

7. Schwoebel J, Coslett HB (2005) Evidence for multiple, distinct representations of the human body. J Cogn Neurosci 17: 543-553.

8. Cash TF, Deagle EA $3^{\text {rd }}$ (1997) The nature and extent of body-image disturbances in anorexia nervosa and bulimia nervosa: A meta-analysis. Int $J$ Eat Disord 22: 107-125.

9. Hrabosky JI, Cash TF, Veale D, Neziroglu F, Soll EA, Garner DM, et al. (2009) Multidimensional body image comparisons among patients with eating disorders, body dysmorphic disorder, and clinical controls: A multisite study. Body Image 6: 155-163.

10. Ruth HS-M, Debra LF, Douglas T, Bruce B, George BS, Stephen RD (2004) Changes in weight and body image over time in women with eating disorders. Int J Eat Disord 36: 315-327.

11. Stice E, Shaw HE (2002) Role of body dissatisfaction in the onset and maintenance of eating pathology: A synthesis of research findings. J Psychosom Res 53: 985-993.

12. Urgesi C, Fornasari L, De Faccio S, Perini L, Mattiussi E, et al. (2011) Body schema and self-representation in patients with bulimia nervosa. J Eat Disord 44: $238-48$.

13. Elsner RJF (2002) Changes in eating behavior during the aging process. Eat Behav 3: 15-43.

14. Monda M, Pittman QJ (1993) Cortical spreading depression blocks prostaglandin E1 and endotoxin fever in rats. Am J Physiol 264: R456-459.

15. Monda M, Amaro S, Sullo A, De Luca B (1994) Posterior hypothalamic activity and cortical control during the PGE1 hyperthermia. Neuroreport 6: 135-139.

16. Monda M, Amaro S, Sullo A, De Luca B (1995) Injection of muscimol in the posterior hypothalamus reduces the PGE1-hyperthermia in the rat. Brain Res Bull 37: 575-580.

17. Monda M, Viggiano A, Viggiano A, Fuccio F, De Luca V (2004) Injection of orexin A into the diagonal band of Broca induces sympathetic and hyperthermic reactions. Brain Res 1018: 265-271.

18. De Luca V, Viggiano E, Messina G, Viggiano A, Borlido C, et al. (2008) Peripheral amino acid levels in schizophrenia and antipsychotic treatment. Psychiatry Investig 5: 203-208.

19. Viggiano A, Vicidomini C, Monda M, Carleo D, Carleo R, et al. (2009) Fast and low-cost analysis of heart rate variability reveals vegetative alterations in noncomplicated diabetic patients. J Diabetes Complications 23: 119-123.

20. Viggiano A, Nicodemo U, Viggiano E, Messina G, Viggiano A, et al. (2010) Mastication overload causes an increase in $\mathrm{O} 2$ - production into the subnucleus oralis of the spinal trigeminal nucleus. Neuroscience 166: 416-421.

21. Messina G, De Luca V, Viggiano A, Ascione A, lannaccone T, et al. (2013) Autonomic nervous system in the control of energy balance and body weight: personal contributions. Neurol Res Int 2013: 639280.

22. Stroebele N, De Castro JM (2004) Effect of ambience on food intake and food choice. Nutrition 20: 821-838

23. Vögele C, Gibson L (2010) Mood, emotions and eating disorders. In Agras WS (Ed.), Oxford Handbook of Eating Disorders. Series: Oxford Library of Psychology 180-205

24. American Psychiatric Association (2013) Diagnostic and Statistical Manual of Mental Disorders Fifth Edition. American Psychiatric Publishing, Washington, DC.

25. Allebeck P, Hallberg D, Espmark S (1976) Body image--an apparatus for measuring disturbances in estimation of size and shape. J Psychosom Res 20: 583-589.

26. Freeman RJ, Beach B, Davis R, Solyom L (1985) The prediction of relapse in bulimia nervosa. J Psychiatr Res 19: 349-53.

27. Touyz SW, Beumont PJV, Collins JK, Cowie I (1985) Body shape perception in bulimia and anorexia nervosa. Int J Eat Disord 4: 261-265.

28. Powers PS, Schulman RG, Gleghorn AA, Prange ME (1987) Perceptual and cognitive abnormalities in bulimia. Am J Psychiatry 144: 1456-1460.

29. Oldfield RC (1971) The assessment and analysis of handedness: the Edinburgh inventory. Neuropsychologia 9: 97-113. 
Citation: Chieffi S, lavarone A, La Marra M, Messina G, Villano I, et al. (2015) Memory for Proprioceptive Targets in Bulimia Nervosa. J Psychiatry 18: 297 doi: 10.4172/2378-5756.1000297

30. Chieffi S, Allport DA (1997) Independent coding of target distance and direction in visuo-spatial working memory. Psychol Res 60: 244-250.

31. Chieffi S, Allport DA, Woodin M (1999) Hand-centred coding of target location in visuo-spatial working memory. Neuropsychologia 37: 495-502.

32. Carrozzo M, Mclntyre J, Zago M, Lacquaniti F (1999) Viewer-centered and body-centered frames of reference in direct visuomotor transformations. Exp Brain Res 129: 201-210.

33. Bridgeman B (1991) Separate visual representations for perception and for visually guided behavior. In: Ellis SR (Ed.), Pictorial communication in virtual and real environments 316-327.

34. Chieffi S, Gentilucci M, Allport A, Sasso E, Rizzolatti G (1993) Study of selective reaching and grasping in a patient with unilateral parietal lesion. Dissociated effects of residual spatial neglect. Brain 116: 1119-1137.

35. Chieffi S (1996) Effects of stimulus asymmetry on line bisection. Neurology 47 1004-1008.

36. Gentilucci M, Chieffi S, Deprati E, Saetti MC, Toni I (1996) Visual illusion and action. Neuropsychologia 34: 369-376.

37. Chieffi S (1999) Influence of perceptual factors on line bisection. Cortex 35 523-536.

38. Chieffi S, Ricci M, Carlomagno S (2001) Influence of visual distractors on movement trajectory. Cortex 37: 389-405.

39. Chieffi S, Ricci M (2002) Influence of contextual stimuli on line bisection Percept Mot Skills 95: 868-874.

40. Chieffi S, Conson M, Carlomagno S (2004) Movement velocity effects on kinaesthetic localisation of spatial positions. Exp Brain Res 158: 421-426.

41. Chieffi S, lavarone A, Viggiano A, Monda M, Carlomagno S (2012) Effect of a visual distractor on line bisection. Exp Brain Res 219: 489-498.
42. Chieffi S, lachini T, lavarone A, Messina G, Viggiano A, et al. (2014) Flanker interference effects in a line bisection task. Exp Brain Res 232: 1327-1334.

43. Chieffi S, lavarone A, laccarino L, La Marra M, Messina G, et al. (2014) Agerelated differences in distractor interference on line bisection. Exp Brain Res 232: 3659-3664

44. Viggiano A, Chieffi S, Tafuri D, Messina G, Monda M et al. (2014) Laterality of a second player position affects lateral deviation of basketball shooting. J Sports Sci 32: 46-52.

45. McCloskey DI (1978) Kinesthetic sensibility. Physiol Rev 58: 763-820.

46. Ferrell WR, Gandevia SC, McCloskey DI (1987) The role of joint receptors in human kinaesthesis when intramuscolar receptor cannot contribute. J Physiol 386:63-71.

47. Lackner JR (1988) Some proprioceptive influences on the perceptual representation of body shape and orientation. Brain 111:281-297.

48. Delvenne V, Goldman S, Simon Y, De Maertelaer V, Lotstra F (1997) Brain hypometabolism of glucose in bulimia nervosa. Int J Eat Disord 21: 313-320.

49. Delvenne V, Goldman S, De Maertelaer V, Lotstra F (1999) Brain glucose metabolism in eating disorders assessed by positron emission tomography. Int J Eat Disord 25: 29-37.

50. Botez MI (1987) Le syndrome parietal. in: Botez M (Ed.) Neuropsychologie Clinique et Neurologie du Comportement 135-154.

51. Horne RL, Van Vactor JC, Emerson S (1991) Disturbed body image in patients with eating disorders. Am J Psychiatry 148: 211-215.

52. Berlucchi G, Aglioti S (1997) The body in the brain: neural bases of corporea awareness. Trends Neurosci 20: 560-564. 